\title{
CAPITAL SOCIAL E PADRÕES DE PARTICIPAÇÃO POLÍTICO-SOCIAL EM IJUÍ - RS
}

Dejalma Cremonese

\section{Resumo}

O objetivo deste artigo é examinar os níveis de participação político-social do município de Ijuí - Noroeste do Estado do Rio Grande do Sul - Brasil. A hipótese principal é que práticas cada vez menos recorrentes de ações cívicas (participativas, associativas e de confiança) entre os membros da comunidade nas últimas décadas constituem a principal causa da variação negativa do capital social do município. 0 referencial teórico e metodológico utilizado neste artigo segue a abordagem do capital social, proposta por Robert Putnam. A segunda parte analisa os resultados do survey aplicado no ano de 2005 (400 entrevistas). A comparação longitudinal entre o survey de 2005 com o de 1968 indica o declínio de manifestações cívicas com a diminuição da participação política convencional, altos índices de desconfiança, redução do associativismo e cooperação. Estes resultados comprovam a hipótese central da variação negativa do capital social em Ijuí.

Palavras-chave: Capital Social; Participação; Democracia.

\begin{abstract}
The main objective of this paper is to examine the political and social participation levels in the city of Ijuí - northwest Rio Grande do Sul - Brazil. The central hypothesis is that practices of civic action are declining (associations, participants and institutional and interpersonal trust) among the members of the community, in the last decades, being these the reasons for the negative variation of social capital in the city. The paper utilizes Putnam's theoretical and methodological proposal. The second part analyzes the results of a survey research which consisted of 400 interviews in 2005. The result of this research was compared with a survey research conducted in 1968 in order to establish longitudinal comparisons. The longitudinal comparisons between 1968 and 2005, indicates the decline of civic manifestations as well as the reduction of conventional political participation, high levels of distrust reduction of associativity and cooperation. Theses results are consistent with the hypothesis of this dissertation about the negative variation of social capital in Ijuí.
\end{abstract}

Keywords: Social Capital; Participation; Democracy.

\section{Introdução}

Este estudo tem como objetivo analisar os níveis de participação político-social em âmbito local, ao tratar, especificamente, do município de Ijuí - Noroeste do Estado do Rio Grande do Sul. Para alcançar esse objetivo, propõe-se utilizar uma abordagem teórica (marco teórico-conceitual) fundamentada na abordagem do capital social e de suas principais variáveis: 


\section{A SITUAÇÃO DAS AMÉRICAS: \\ DEMOCRACIA, CAPITAL SOCIAL E EMPODERAMENTO}

"participação comunitária", "participação política convencional", "participação política não convencional", "confiança interpessoal" e "satisfação com a democracia". As variáveis serão postas em relação com índices que sintetizam informações sobre variáveis socioeconômicas e atitudinais das pessoas, buscando traçar o perfil do cidadão ijuiense (níveis de educação, renda, trabalho, etnia e religião).

A análise teórica foi testada via pesquisa empírica através da análise dos resultados de um survey aplicado na população urbana de Ijuí em 2005. Nesse survey foi evidenciado o perfil atitudinal dos ijuienses (níveis de confiança, cooperação, associativismo, participação e comportamento político). Foi possível fazer também um estudo comparativo longitudinal com os resultados de outro survey aplicado no mesmo município no final da década de $1960^{1}$.

O artigo está dividido em duas seções: a primeira apresenta uma definição conceitual sobre o capital social e participação; a segunda apresenta informações referentes à participação político-social de Ijuí .

\section{Capital Social e Participação: uma explanação conceitual}

O conceito de capital social foi inaugurado por Lyda Hanifan no início do século XX com o artigo "The rural school community center" (1916). A autora definiu-o como a unidade social que resulta das relações entre indivíduos e famílias. O conceito voltou a ser utilizado na segunda metade do século, obtendo, desde então, uma rápida repercussão. Entretanto, apesar de ter passado a apresentar grande expressão entre as Ciências Sociais, há certa dificuldade de definí-lo, pois seus teóricos partem de duas perspectivas: uma micro e outra macrossocial. Sendo assim, esse conceito não é homogêneo e ainda vem sendo desenvolvido.

Destaca-se que, apesar de ter sido usado pela primeira vez por Hanifan, o conceito de capital social já havia sido perceptível, de forma implícita, em 1835 na obra "A Democracia na América", de Tocqueville (1969). Esse autor, mesmo sem ter usado o referido termo, deixou-o presente ao falar da comunidade cívica que tornava peculiar os Estados Unidos, ao fazer uma relação entre vida associativa e democracia. Tocqueville apontou a participação dos indivíduos em associações comunitárias - que se pode traduzir pelo conceito de capital social - como influência ao funcionamento e consolidação da democracia.

Assim, após a indicação tocquevilleana de capital social e a inauguração de tal conceito por Hafinan, este esteve submergido na academia, até ser resgatado, em 1961, pela urbanista Jane Jacobs, que

\footnotetext{
${ }^{1}$ Conferir o survey aplicado por Hélgio Trindade e equipe no município de Ijuí no ano de 1968.

2 Informações recentes ratificam a erosão da sociabilidade do ijuiense, o declínio da participação política convencional e não convencional, também da participação comunitária, bem como a estagnação do PIB e do IDH do município.
} 
utilizou o termo para referir-se às redes sociais que são insubstituíveis à vida das cidades.

Procedido o resgate do termo por Jacobs, diversos autores passaram a fazer uso desse conceito. Seus teóricos mais reconhecidos na academia são Pierre Bourdieu, James Coleman, Robert Putnam e Francis Fukuyama. Os dois primeiros autores partem de uma perspectiva individualista na sua metodologia, através da análise de um panorama microssocial, enquanto que Putnam e Fukuyama assemelham-se pela concepção holística, que observa o capital social como uma entidade coletiva, por meio de um exame de nível macrossocial (BAQUERO, 2003). Para Fukuyama (2002), todas as sociedades possuem algum capital social, sendo que a variação desse elemento que diferencia cada uma delas é denominada por ele de "raio de confiança", uma vez que representam atitudes facilitadoras de ações coletivas em torno de metas comuns. O autor afirma, no entanto, que "[...] medir o estoque total de relações sociais cooperativas com base em normas de honestidade e reciprocidade não é tarefa pequena" (FUKUYAMA, 2002, p. 158).

Pierre Bourdieu foi o primeiro a falar de capital social na literatura sociológica, sendo, por consequência, responsável pela maior expressão que o termo adquiriu a partir da década de 1980 entre os cientistas sociais. Esse autor define capital social como o "[...] agregado dos recursos atuais ou potenciais, vinculados à posse de uma rede duradoura de relações de familiaridade ou reconhecimento mais ou menos institucionalizadas" (BOURDIEU apud HIGGINS, 2005, p. 30).

A perspectiva de Bourdieu, embora diferente, influenciou a compreensão sustentada por outros teóricos desse conceito, como Coleman, Putnam e Fukuyama. James Coleman é um dos autores que mais contribuiu para o desenvolvimento do conceito de capital social a partir do artigo, escrito em 1988, "The social capital in the creation of human capital". Diferente de Bourdieu, que parte de um foco político, Coleman tem por base um foco utilitarista ao entender o capital social em termos funcionais, ou seja, para o autor o capital social consiste em um meio para que os atores individuais, através das relações sociais, atinjam suas metas, satisfazendo seus interesses. Assim sendo, o capital social seria "[...] a habilidade das pessoas trabalharem juntas, em grupos e organizações, para atingir objetivos comuns" (COLEMAN, 1988, p. 95).

Como foi possível perceber, Bourdieu e Coleman, embora divergindo em alguns aspectos, partem de uma análise microssocial na concepção de capital social, definindo tal conceito a partir das redes de relações entre indivíduos. Essa perspectiva se diferencia da concepção de Putnam e Fukuyama, que analisam tal termo sob uma ótica macrossocial. Sob essa perspectiva, na década de 1990, Robert Putnam popularizou o conceito na Ciência Política, ao defender que o capital social diz respeito "[...] a características da organização social, como confiança, normas e sistemas, que contribuam para aumentar a eficiência da sociedade facilitando as ações coordenadas" (PUTNAM, 2002, p. 177). Para esse autor existem modalidades 


\section{A SITUAÇÃO DAS AMÉRICAS: \\ DEMOCRACIA, CAPITAL SOCIAL E EMPODERAMENTO}

de confiança e que podem ser destacadas da seguinte forma: confiança interpessoal, que, de acordo com Putnam, é considerada como veículo do progresso social; confiança social nas elites (líderes sociais, econômicos e políticos, acesso e manutenção em posições de direção) é um recurso que contribui para a coesão, a participação e a integração social; e confiança nos meios de comunicação, que constituem um recurso para a representação dos anseios dos cidadãos. Putnam chega a tal conclusão por intermédio de seu estudo - de mais de 20 anos - sobre a Itália, que resultou no livro "Comunidade e Democracia: a experiência da Itália moderna", no qual conclui que as diferenças de desempenho dos governos regionais na Itália se davam em razão de umas regiões apresentarem mais comunidade cívica do que outras. Sendo assim, esse pensador caracteriza-se por relacionar capital social e desenvolvimento institucional.

Destaca-se aqui que há três modos possíveis de capital social: capital social bonding, capital social bridging e capital social linking. O primeiro diz respeito aos grupos homogêneos, envolvendo vínculos entre agentes da mesma posição, o que limita os efeitos positivos desse capital. O segundo refere-se aos laços entre pessoas de grupos sociais distintos, representando o ideal de sociedade cívica na concepção de Putnam, pois, segundo o autor, influencia em um Estado eficiente. O terceiro, por sua vez, refere-se às relações verticais entre pobres e pessoas que têm o poder de decisão em organizações formais. Sendo assim, os capitais de tipo bridging e linking são os que mais colaboram para incrementar a qualidade democrática.

Além do mais, a noção de capital social tem a ver com a geração de confiança entre os indivíduos, o que emerge de interações frequentes. A participação em associações seria o elemento catalisador deste tipo de confiança. Nesse sentido, segundo Baquero (2001), o capital social é visto, na economia contemporânea, como um elemento que potencializa a inovação via construção de redes organizacionais que ajudam a desenvolver a habilidade de trabalhar cooperativamente para a promoção de ganhos produtivos mútuos. Para Baquero (2000), a confiança é um componente básico do capital social. Quanto maior a confiança, maior é a probabilidade de cooperação e de participação política. Em síntese, a confiança interpessoal e a participação, nas instituições sociais e políticas são as principais facilitadoras de ações coletivas em torno de metas comuns.

A participação integra o cotidiano da coletividade humana. Ao longo da vida e em diversas ocasiões somos levados, por desejo próprio ou não, a participar de grupos e de atividades. O ato de participar, de tomar parte, revela a necessidade que os indivíduos têm em associar-se na busca de alcançar objetivos que Ihes seriam de difícil consecução ou até mesmo inatingíveis caso fossem perseguidos individualmente, de maneira isolada (ALLEBRANDT, 2002).

Das diferentes formas de participação, pode-se definir a participação política como o número e a intensidade de indivíduos e grupos envolvidos na tomada de decisões. Desde o tempo dos antigos gregos, a participação 
constituiu-se idealmente no encontro de cidadãos livres debatendo publicamente e votando sobre decisões de governo. A teoria mais simples sempre foi a de que o bom governo depende de altos níveis de participação (OUTHWAITE e BOTTOMORE, 1996).

Há, no entendimento de Avelar e Cintra (2004), três canais de participação política. O primeiro: canal eleitoral - diz respeito a formas de participação política em atividades como os atos de votar, frequência em reuniões de partidos, convencer as pessoas a optar por certos candidatos e partidos, contribuir financeiramente para campanhas eleitorais, arrecadar fundos, ser membro de cúpula partidária, candidatar-se. O segundo: canais corporativos - tem a ver com a representação de interesses privados no sistema estatal, organizações profissionais e empresariais, as instâncias do Judiciário e dos Legislativos. O terceiro: a participação pelo canal organizacional, que abrange as atividades que se dão no espaço não institucionalizado da política, como os movimentos sociais (étnicos, de gênero, opção sexual...). Avelar e Cintra (2004) conclui dizendo que "[...] o cidadão interessado pela política se envolve ou atua tanto nos modos de participação convencional e não-convencional, pelos canais eleitorais ou organizacionais" (p. 227).

Da mesma forma, segundo a posição de Alves e Viscarra (2005), a participação política pode ocorrer, igualmente, de três formas distintas: a) a participação convencional, utilizada através de meios institucionais, autorizada ou regulada por leis ou normas, como votar em eleições, militância partidária, entre outras; b) a participação não convencional, referente às ações que utilizam meios extra-institucionais que contrariam as regras estabelecidas, incluindo ocupações de prédios ou terrenos, obstrução de vias públicas, etc.; c) participação comunitária, que possui o maior apoio de comunidades locais, como, por exemplo, ONGs, movimentos de bairros, voluntariado e associações comunitárias, que, desde a década de 1980, estão aumentando significativamente no Brasil. Em outras palavras, a participação comunitária e a participação não convencional compreendem todas aquelas formas de participação não institucionalizadas, principalmente a eleitoral, que beneficiam o conjunto de cidadãos e que não vai contra uma lógica ou as práticas democráticas. Portanto, juntamente com a participação em associações com distintas características, ficam incluídas as ações coletivas desafiantes, convencionais e não convencionais, tais como os protestos e as greves $^{3}$. Essas relações comunitárias convencionais tendem a ser, em geral, positivas a partir do pressuposto de que quanto maior a confiança, maior é a disposição para participar (BAQUERO, 2005 apud VALDIVIESO, 2009). Presume-se que, quanto maior for a participação em associações comunitárias, maior será a disposição a informar-se, a discutir e a participar na política. Assim, o capital social tem relação com as identidades que

\footnotetext{
3 Diferentes estudos apontam para a importância da participação política para a estabilidade democrática. Cf. Valdivieso (2009), Borba (2005), Norris (2002) e Baquero (2005).
} 


\section{A SITUAÇÃO DAS AMÉRICAS: \\ DEMOCRACIA, CAPITAL SOCIAL E EMPODERAMENTO}

expressam competências sociais aptas para as ações coletivas como práticas que têm influência na disposição do indivíduo em participar.

\section{A participação político-social do ijuiense}

Esta seção procura demonstrar o declínio da participação político-social em Ijuí nas últimas décadas. O estudo comprovará a hipótese principal de que práticas cada vez menos recorrentes de ações cooperativas, associativistas, participativas e comunitárias podem estar associadas ao declínio do capital social de um município ou região.

Em linhas gerais, percebe-se que o comportamento político do ijuiense deixou de ser associativo, cooperativo e empreendedor, transformando-se num comportamento individualista, marcado pela desconfiança e pela indiferença, o que se reflete inclusive na estagnação econômica do município. O Movimento Comunitário de Base (MCB), importante mecanismo de mobilização e de participação dos pequenos agricultores nos anos 1960, já não existe e há sérias dificuldades para a manutenção e o incremento de instituições e de outros instrumentos de participação comunitária, como os conselhos municipais, sindicatos e cooperativas, além da crise econômica que afeta a própria universidade regional, a Unijuí, a mais importante instituição educacional da região.

Através da análise dos resultados do survey (2005), foi possível avaliar a variação dos níveis de participação político-social, bem como conhecer um pouco mais do comportamento político do ijuiense. O plano amostral da pesquisa (400 entrevistas) atingiu uma população composta de $47 \%$ de homens e $53 \%$ de mulheres, sendo que $60,8 \%$ cursaram o ensino fundamental (completo ou incompleto); $23 \%$ cursaram ou cursam o nível médio (completo ou incompleto) e apenas 14\% estão cursando ou concluíram o curso superior. No que se refere à economia, os dados apontam para uma baixa renda per capita entre os ijuienses, em que $51,6 \%$ ganham até 1 salário mínimo; 43,5\% ganham de 1 a 3 salários mínimos, menos de $3 \%$ da população ganham até 5 salários mínimos e uma minoria de 1,9\% ganham mais de 5 salários mínimos. Esses dados refletem o baixo poder aquisitivo da maioria da população ijuiense. Perguntou-se, também, se a população conseguia poupar algum dinheiro em cada mês, para o que a resposta de $54,1 \%$ (mais da metade da população) foi que não conseguem poupar nenhum dinheiro. No que se refere à ocupação do ijuiense, percebeu-se que quase a metade da população $(45,1 \%)$ não está empregada, trabalha por contra própria (trabalho informal) ou, ainda, é estudante ou dona de casa. Esses mesmos entrevistados indicaram os principais problemas enfrentados pelo Brasil nos últimos tempos: para mais de $60 \%$ da população são problemas sociais ou econômicos, como o desemprego (com 31\%) e fome e miséria (com 9,5\%), entre outros.

A pesquisa apontou para uma predominância da etnia branca no município, sendo que $80 \%$ fazem parte deste grupo. Já os entrevistados que 
responderam serem morenos/pardos/mestiços somam 15,1\%. A religião predominante no município é a católica, com $61 \%$, seguida pela evangélica pentecostal, com $23 \%$ da população.

Dentro da percepção política dos ijuienses, questionou-se, inicialmente, sobre a avaliação dos serviços prestados no município: para $66 \%$ da população o transporte coletivo é considerado bom, juntamente com a educação, $63 \%$. Por outro lado, os serviços que obtiveram as piores avaliações (ruim/péssimo) junto à comunidade foram o saneamento, com $63,5 \%$, e a segurança, com $73,3 \%$. Também para $46,8 \%$ dos entrevistados 0 Estado é ineficiente, pois aplica mal os recursos. A satisfação com o funcionamento da democracia em Ijuí é baixa, pois apenas $14 \%$ estão satisfeitos com o seu funcionamento, enquanto que $82 \%$ estão pouco satisfeitos ou insatisfeitos. É baixa, igualmente, a identificação partidária do eleitor ijuiense, em que somente $32,5 \%$ se identificam com algum partido político, enquanto que $67,5 \%$, não. A falta de civismo é igualmente notável frente à obrigatoriedade do voto: $26 \%$ dos ijuienses votam somente porque é obrigatório e, se o voto fosse facultativo, 34\% não votariam nas eleições. Assim, percebe-se que a tendência é a de que as pessoas tendem a participar somente quando é necessário. Além disso, ainda existem manifestações de clientelismo, na medida em que $7,8 \%$ aceitariam dinheiro ou cesta básica em troca do voto.

Outro resultado relevante deste estudo é a comprovação da baixa participação social e política e da baixa confiança interpessoal e institucional, demonstradas pela população ijuiense. As pessoas que vivem em Ijuí até estão predispostas a ajudar, mas, concretamente, há poucos gestos de participação ou de colaboração comunitária. No que se refere à participação em grupos e organizações sociais, $32,5 \%$ responderam que participam, enquanto que a maioria (67\%) não participa de grupos ou organização social. Sobre a ajuda vicinal, os dados indicam que a maioria (64\%) dos entrevistados afirmou que podiam contar com os vizinhos para cuidar dos filhos e da casa, caso necessitassem. Percebe-se que o ijuiense até pode contar com os vizinhos, mas isso não significa que exista confiança entre eles: $55,8 \%$ dos entrevistados responderam que os vizinhos não são confiáveis, da mesma forma que $30,3 \%$ responderam que nunca podem confiar nas pessoas que moram no bairro.

Sobre a participação política, os dados demonstram que a sociedade ijuiense participa mais de instituições de cunho comunitário, tal como associação religiosa $(68,3 \%)$, associação comunitária $(30,1 \%)$, Orçamento Participativo $(30,1 \%)$, associação sindical $(19,5 \%)$, Conselhos Populares $(17,5 \%)$ e ONGs $(9,1 \%)$. A média de participação na forma comunitária fica em torno de $31 \%$. A segunda forma de participação política da sociedade ijuiense é a forma convencional de comícios $(40,1 \%)$, reuniões políticas $(24,3 \%)$ e partidos políticos $(18,3 \%)$, em que a média de participação convencional é de $26,6 \%$. Por último aparece a forma de participação política não convencional, com abaixo-assinados $(51,3 \%)$, manifestação e protestos 


\section{A SITUAÇÃO DAS AMÉRICAS: \\ DEMOCRACIA, CAPITAL SOCIAL E EMPODERAMENTO}

$(26,5 \%)$, greves $(18,3 \%)$ e ocupação de prédios ou terrenos públicos $(3,8 \%)$, em que a média de participação da sociedade ficou em torno de $25 \%$.

Como foi explicitado anteriormente, a confiança interpessoal e nas instituições apresenta indicadores reduzidos em Ijuí. O percentual de confiança entre os ijuienses é de apenas $27 \%$, enquanto que $71,5 \%$ dos entrevistados responderam que não se pode confiar nas pessoas.

As instituições sociais mais confiáveis são a família (90\%) e as igrejas $(60,8 \%)$, o que comprova que a confiabilidade fica restrita ao nível nuclear. Por outro lado, as instituições políticas foram as instituições com os mais altos índices de pouca e não confiança: dentre os mencionados, os mais desacreditados foram o governo municipal $(85,5 \%)$, o governo federal $(89 \%)$, o governo estadual $(92,5 \%)$, a Câmara Municipal $(93,8 \%)$, a Assembleia Legislativa $(94,6 \%)$, os partidos políticos $(94,8 \%)$ e o Congresso Nacional $(97,8 \%)$. Além da falta de credibilidade, percebe-se o pouco interesse por política, pois $37,3 \%$ não se interessam. A pesquisa demonstrou igualmente que, quanto maior a instrução das pessoas, maior a informação e o interesse por política.

Ainda no quesito sociabilidade, tem-se um declínio acentuado da participação social da população de Ijuí nas últimas décadas. Depoimentos de lideranças locais apontam para o declínio do caráter comunitário da sociedade ijuiense, além da massificação, competição, desemprego e individualismo, que atingem a todos indistintamente, como consequência da supremacia do mercado. Esse é o enfoque do depoimento do professor universitário Suimar Bressan:

Ijuí perdeu seu perfil comunitário e transformou-se numa sociedade de massas. Vivemos também um momento de hegemonias do mercado (ou politização do mercado) no sentido de que as questões sociais e demandas individuais se resolvem segundo a iniciativa de cada um nesse espaço essencialmente competitivo. A reestruturação produtiva representou (e continua) uma destruição de empregos com reflexos bastante significativos no sindicalismo. Também se deve considerar a crise do cooperativismo, que foi um significativo espaço de discussão e mobilização sobre questões da agricultura regional, da modernização e da dependência. Em síntese, a mobilização intensa dos anos $50 / 60$ - até início dos anos 80 - estava vinculada ao "espírito" da época: a luta pelas Reformas de Base e, posteriormente, a luta contra a ditadura. Talvez se deva considerar que neste novo tempo as formas de manifestações, mobilizações e organizações sejam outras ${ }^{4}$.

A ideia do individualismo que paira na comunidade ijuiense, detectada na posição de diferentes líderes comunitários, ainda persiste, como fica claro

\footnotetext{
${ }^{4}$ Entrevista concedida a Dejalma Cremonese, em Ijuí, 13 de outubro de 2005.
} 
no comentário emitido recentemente pelo professor Lauri Basso. Para ele, há um esforço de determinadas instituições ou entidades que buscam incessantemente se salvar, mas, no geral, é uma saída essencialmente individualista:

\begin{abstract}
Ou seja, uma luta individual de salve-se quem puder. A busca por estratégias para a comunidade no seu conjunto desaparece. Isso pode revelar sim uma diminuição da presença dos valores característicos do capital social de uma comunidade. Ijuí consegue crescer, ainda acima da média, mas como conseqüência de iniciativas individuais (empresas). Temos na região muitos municípios pequenos que conseguem arraigar um pouco mais seu povo, mas com as eleições e troca de governos e de partidos, sempre há um recomeçar, ou seja, revela ausência de construção social de um futuro próspero para a comunidade. Sempre volta a marca do individualismo ${ }^{5}$.
\end{abstract}

Da mesma forma, a participação na resolução dos problemas locais tem diminuído, igualmente, nas últimas décadas. Uma análise dos resultados da pesquisa de 1968, comparada aos resultados da pesquisa 2005, aponta para uma diminuição da tentativa de resolução dos problemas locais/bairro/comunidade junto com outras pessoas. Em 1968, 91,8\% dos entrevistados responderam que tentaram resolver de alguma forma os problemas, contra apenas $32,8 \%$ em 2005. Uma diminuição de 59 pontos percentuais da participação na tentativa de resolver os problemas locais do bairro/comunidade junto com outras pessoas.

Tabela 1 - Participação na solução de problemas (1968-2005) (\%)

\begin{tabular}{l|c|c}
\hline & $\mathbf{1 9 6 8}$ & $\mathbf{2 0 0 5}$ \\
\hline Sim & 91,8 & 32,8 \\
\hline Não & 6,3 & 65,8 \\
\hline NS/NR & 1,9 & 1,5 \\
\hline Total N= & 367 & 400 \\
\hline
\end{tabular}

Fonte: Trindade (1968) e dados elaborados pelo autor a partir da Pesquisa

Desenvolvimento Sustentável e Capital Social-NIEM/ NUPESAL/UNIJUÍ - 2005.

$\mathrm{Na}$ questão da segurança pública, o ijuiense desaprova o serviço. Apenas $24,8 \%$ acham o serviço "bom", contra $73,3 \%$ que avaliam o serviço como "ruim" ou "péssimo". Esse percentual negativo acaba afetando a qualidade de vida dos ijuienses, pois, quando as pessoas não se sentem seguras, tendem a desconfiar mais umas das outras ou até mesmo deixam de ir a lugares que estavam acostumados a frequentar.

Essa redução da participação ocorre porque o incremento da violência difusa pode estar associado à redução na qualidade de vida de uma

\footnotetext{
${ }^{5}$ Entrevista concedida a Dejalma Cremonese, em Ijuí, 13 de outubro de 2005.
} 


\section{A SITUAÇÃO DAS AMÉRICAS: \\ DEMOCRACIA, CAPITAL SOCIAL E EMPODERAMENTO}

determinada região ou município, podendo significar, igualmente, uma redução da variação do capital social. Outros estudos apontam, igualmente, para a mudança dos hábitos cotidianos das pessoas para reduzir o risco a que estariam submetidos. As pessoas limitam os locais onde transitam, deixam de ir a locais de que gostam, evitam usar meios de transporte coletivo, evitam sair de casa à noite, gastam altas somas de recursos na proteção de suas residências, passam a adquirir armas e, muitas vezes, a andar armadas (MINISTÉRIO DA JUSTIÇA, 2003).

Dentro desse contexto, o resultado da pesquisa de 2005 demonstrou que, em Ijuí, a maioria dos entrevistados (50\%) sente-se insegura ao andar nas ruas, pois $11 \%$ dos ijuienses já sofreram algum tipo de violência (assalto) nos últimos tempos e cerca de $66 \%$ dos entrevistados conhecem alguma pessoa que já sofreu alguma violência física. Perguntou-se, igualmente, quais os possíveis meios de evitar tais situações: a maioria dos entrevistados respondeu que devem sair em companhia de outra pessoa $(72,8 \%)$, evitar sair depois que anoitece $(62,8 \%)$ ou até mesmo pedir proteção da polícia $(62,3 \%)$, mesmo que esta seja ineficiente.

O bom nível da qualidade de vida também é uma manifestação de capital social de uma comunidade e pode ser comprovado a partir da satisfação, realização e segurança frente ao futuro. Em Ijuí, porém, os resultados demonstrados através da pesquisa são preocupantes. Mais de $30 \%$ da população afirmam estar insatisfeitos, 43,5\% responderam estar inseguros frente ao futuro e $31,8 \%$ responderam estar frustrados.

Além dos aspectos já mostrados, que evidenciam a variação negativa do capital social em Ijuí nos últimos 30 anos, percebe-se que a sociedade ijuiense retrocedeu, igualmente, no aspecto associativo, na cooperação e na participação. A comunidade ijuiense não consegue mais aglutinar forças para resolver os problemas comuns. As instituições sociais e políticas (poder público e partidos), Universidade e Associação Comercial de Ijuí (ACI) não trabalham de forma integrada. As resoluções dos problemas dão-se de forma individualizada.

A sociedade ijuiense parece estar vivendo o familismo amoral, aquela característica social descrita por Banfield (1958) como uma sociedade onde impera a ausência da virtude cívica, sendo o isolamento e a desconfiança em relação ao outro a característica fundamental. No familismo amoral, a pessoa parece estar unicamente interessada no seu próprio bem-estar e no de sua família, isto é, busca-se "maximizar a vantagem material e imediata da família nuclear; supor que todos os outros agirão da mesma forma" (BANFIELD, 1958, p. 14). Como explicita uma liderança local em entrevista oral: "Geralmente você não encontra parceiros e sim concorrentes [...]. Ijuí trabalha em grupos familiares fechados e, particularmente, tive muita dificuldade de entrar neste grupo quando cheguei aqui anos atrás" ${ }^{\prime 6}$.

\footnotetext{
${ }^{6}$ Entrevista concedida a Dejalma Cremonese, em Ijuí, 22 de maio de 2005.
} 
Da mesma forma, as instituições que foram importantes referências de associativismo, cooperação e participação social nos anos 1960, passam por sérias crises. Segundo o sindicalista Carlos Alberto Dahmer, essa crise está ligada à apropriação de algumas pessoas ou famílias que se perpetuam no poder sem nenhum tipo de alternância:

Penso que possam estar atravessando um processo de crise de identidade, uma vez que a renovação pessoal nestas entidades se dá de maneira muito tímida. A meu ver a apropriação pessoal das entidades não dá a possibilidade de oxigenação necessária. Pois vejamos os exemplos: dirigentes na Cotrijuí, na Ceriluz, na Unijuí, nos Sindicatos (transporte, rural patronal e empregados), CBI (via Prefeitura, é o mesmo grupo no comando há 20 anos). Ao mesmo tempo que não forma novas lideranças, aniquila qualquer movimento de reação a este processo. Pode-se jogar esta mesma avaliação para outros segmentos da sociedade, como ACI, Lions, Clubes Religiosos e de serviços ${ }^{7}$.

Os dados explicitados pela pesquisa apontam também para um crescente êxodo rural que atingiu a Região Noroeste do Estado do Rio Grande do Sul, inclusive o município de Ijuí, nas últimas décadas. Uma das causas desse fenômeno foi o processo de modernização da agricultura (binômio trigo e soja), que priorizou a produção de larga escala em propriedades maiores, expulsando os pequenos agricultores de seus estabelecimentos. A passagem dos anos 1960 para os 1970 foi emblemática, pois, em menos de 20 anos, a população rural/urbana inverteu-se. Em 1960, 66\% da população de Ijuí morava na área rural e 34\% na urbana; nos anos 1970, $61 \%$ passou a viver nas cidades, contra apenas 39\% que permaneceram na área rural. Essa tendência agravou-se nos últimos anos, verificando-se que, em 2005, 14\% da população vivia na área rural contra $86 \%$ na cidade. Em 2010, os dados demonstram que apenas $9 \%$ da população permanecem na área rural, enquanto $91 \%$ moram na área urbana.

Quadro 1 - Evolução da população urbana/rural de Ijuí RS (1960-2005) (\%)

\begin{tabular}{|l|c|c|c|}
\hline & $\mathbf{1 9 6 0}$ & $\mathbf{1 9 7 0}$ & $\mathbf{2 0 0 5}$ \\
\hline Rural & 66 & 34 & 14 \\
\hline Urbana & 39 & 61 & 86 \\
\hline
\end{tabular}

Fonte: IBGE (2010).

Junto com o êxodo rural, a cidade de Ijuí cresceu de maneira desordenada, sem planejamento e organização, quando de imediato deparouse com sérios problemas de habitação, saneamento básico, desemprego e violência. Os novos moradores viram, ao mesmo tempo, sucumbir suas

${ }^{7}$ Entrevista concedida a Dejalma Cremonese, em Ijuí, 22 de maio de 2005.

REVISTA DEBATES, Porto Alegre, v.6, n.1, p. 61-83, jan.-abr. 2012. 


\section{A SITUAÇÃO DAS AMÉRICAS: \\ DEMOCRACIA, CAPITAL SOCIAL E EMPODERAMENTO}

origens interioranas e um maior sentimento de incerteza e dispersão urbana fez deles seres anônimos. Esse problema é comentado por Jaeme Callai:

A sociedade ijuiense complexificou-se nos últimos 50 anos e acabou perdendo suas características camponesas como solidariedade, controle social e vizinhança. A experiência associativa esteve fundada nestes valores tradicionais (é marcante a influência da Igreja na animação de todas essas experiências). A base social foi se alterando por conta de um certo cosmopolitismo que reforça o individualismo; da presença de novos contingentes populacionais deslocados do campo, desenraizados, que produzem um Estado de anomia social (se fosse usar o termo) ${ }^{8}$.

Da mesma forma, para Bernadete Azambuja, o problema do empobrecimento da população rural favoreceu a migração para as cidades. Além disso, essas populações ficaram reféns de políticos tradicionais com seus velhos vícios:

O desmonte de parcelas da população que se fizeram economicamente no período da modernização fora da região. Ou então pelo fechamento de empresas tradicionais; a grande migração para a cidade de Ijuí de parcelas da população empobrecida, o que reitera os esquemas políticos tradicionais - clientelismo, assistencialismo ${ }^{9}$.

Houve um declínio, igualmente, nas manifestações da política convencional, como participação em reuniões políticas, participação em partidos políticos, comícios, declínio da participação nas eleições municipais (1972 - 2004), bem como o baixo interesse por política entre os eleitores.

Constatou-se que a participação em reuniões junto aos partidos políticos declinou sensivelmente entre os eleitores ijuienses. Em 1968, 27,8\% responderam que participavam em reuniões políticas contra $24,3 \%$ em 2005 , ou seja, um decréscimo de 3,5 pontos percentuais na participação nos últimos tempos. Considerando que, nos dias de hoje, o número de partidos políticos é bem maior comparado à época do bipartidarismo do regime militar e que estamos em um regime democrático, esperava-se uma maior participação em reuniões políticas, o que na realidade não acontece.

\footnotetext{
${ }^{8}$ Entrevista concedida a Dejalma Cremonese, em Ijuí, 28 de outubro de 2005.

${ }^{9}$ Entrevista concedida a Dejalma Cremonese, em Ijuí, 14 de outubro de 2005.
} 
Tabela 2 - Participação em reuniões políticas (\%)

\begin{tabular}{l|c|c}
\hline & $\mathbf{1 9 6 8}$ & $\mathbf{2 0 0 5}$ \\
\hline Sim/Já participou & 27,8 & 24,3 \\
\hline Não & 72 & 75 \\
\hline Total & 367 & 400 \\
\hline
\end{tabular}

Fonte: Trindade (1968) e dados elaborados pelo autor a partir da Pesquisa Desenvolvimento Sustentável e Capital Social - NIEM/NUPESAL/UNIJUÍ - 2005.

Da mesma forma, ocorreu uma diminuição na participação em partidos políticos. Em 1968, 20,5\% responderam que participavam, contra 18,3\% de 2005, ou seja, uma diminuição de 2,2 pontos percentuais.

Tabela 3 - Participação em partidos políticos (\%)

\begin{tabular}{l|c|c}
\hline & $\mathbf{1 9 6 8}$ & $\mathbf{2 0 0 5}$ \\
\hline Sim/Já participou & 20,5 & 18,3 \\
\hline Não & 79,4 & 81,5 \\
\hline Total & 367 & 400 \\
\hline
\end{tabular}

Fonte: Trindade (1968) e dados elaborados pelo autor a partir da Pesquisa

Desenvolvimento Sustentável e Capital Social - NIEM/NUPESAL/UNIJUÍ - 2005.

A diminuição na participação em campanhas eleitorais (comícios) também se evidenciou a partir da comparação entre os dois surveys. Em $1968,59,4 \%$ afirmaram que participavam ou já haviam participado, contra $38,7 \%$ que responderam não ter participado. Já nos resultados da pesquisa 2005, o percentual de participação baixou para $40,1 \%$ dos entrevistados que afirmaram participar ou já ter participado, enquanto que 59,5\%, não. 0 decréscimo na participação em comícios ficou em torno de 19 pontos percentuais, bem maiores, portanto, que a participação em reuniões políticas e partidos políticos.

Tabela 4 - Participação em comícios (\%)

\begin{tabular}{l|c|c}
\hline & $\mathbf{1 9 6 8}$ & $\mathbf{2 0 0 5}$ \\
\hline Sim/Já participou & 59,4 & 40,1 \\
Não & 38,7 & 59,5 \\
\hline Total & 367 & 400 \\
\hline
\end{tabular}

Fonte: Trindade (1968) e dados elaborados pelo autor a partir da Pesquisa Desenvolvimento Sustentável e Capital Social - NIEM/NUPESAL/UNIJUÍ - 2005.

Considerando que a diminuição da participação dos eleitores nos pleitos municipais seja uma manifestação de perda de espírito cívico de uma sociedade, constatou-se que em Ijuí os eleitores têm, aos poucos, se afastados das urnas. Um levantamento de dados da participação eleitoral nas eleições municipais de 1996-2008 demonstra uma diminuição do número de comparecimento às urnas. O comparecimento dos eleitores às urnas passou 
de $85,2 \%$ em 1996 para 84,5\% em 2008 (eleições municipais) que, em tese, deveria causar maior mobilização junto ao eleitorado em comparação com as eleições para governador ou presidente.

Gráfico 1 - Evolução da participação eleitoral em Ijuí (Municipais) (1972-2004)

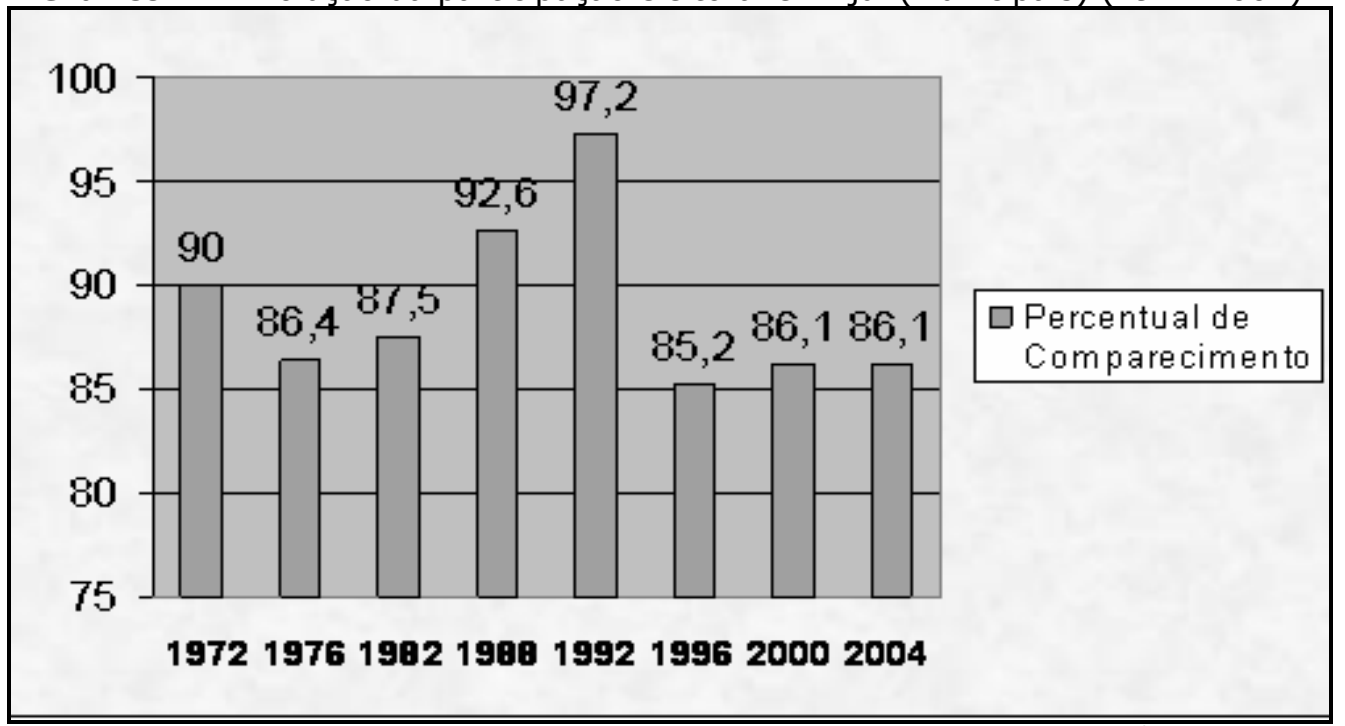

Fonte: Dados elaborados pelo autor a partir de Pesquisa no TRE-RS ${ }^{10}$.

Os dados da pesquisa de Ijuí parecem se assemelhar ao comportamento de outras regiões ou até mesmo de países que têm uma tradição democrática e um melhor desenvolvimento econômico, ou seja, a motivação em acompanhar a política é pouco significativa. Segundo a comparação longitudinal entre as pesquisas aplicadas em Ijuí (1968-2005), percebe-se que o interesse por assuntos ligados à política tem diminuído nos últimos anos, demonstrando o declínio da virtude cívica dos ijuienses, isto é, a ausência de interesse por questões políticas pode ser um primeiro indicativo de ausência de capital social. Em 1968, 29,7\% afirmavam interessar-se por assuntos ligados à política; $31 \%$ afirmaram interessar-se mais ou menos e $38,7 \%$ afirmaram não se interessar por política. Os resultados do survey 2005 demonstram um percentual menor: $26 \%$ responderam que se interessam por política; $36,5 \%$ se interessam mais ou menos e $37,3 \%$ afirmaram não se interessar. Considerando que a pesquisa de opinião de 1968 foi aplicada no período de radicalização do regime militar (fechamento do Congresso, perseguição e tortura), os dados de interesse pela política são considerados altos em relação aos dados da pesquisa de 2005, exatamente por vivermos um tempo de democracia em que, teoricamente, o interesse pela política deveria ser maior.

${ }^{10}$ Disponível em: <http://www.tre-rs.gov.br/>. Acesso em: 14 abr. 2006. 
Tabela 5 - Interesse por política (\%)

\begin{tabular}{l|c|c}
\hline & $\mathbf{1 9 6 8}$ & $\mathbf{2 0 0 5}$ \\
\hline Sim & 29,7 & 26 \\
\hline Mais ou Menos & 31 & 36 \\
\hline Não & 38,7 & 37 \\
\hline Total & 367 & 400 \\
\hline
\end{tabular}

Fonte: Trindade (1968) e dados elaborados pelo autor a partir da Pesquisa Desenvolvimento Sustentável e Capital Social - NIEM/NUPESAL/UNIJUÍ - 2005.

Têm-se mantido no município alguns traços da cultura política convencional com a prática do clientelismo, do paternalismo, do patrimonialismo e do personalismo.

O personalismo pode ser comprovado na pouca alternância das lideranças políticas à frente da Prefeitura nos últimos 20 anos, por exemplo. Desde 1982, o Partido Democrático Trabalhista (PDT), com as famílias Burmann e Heck, tem dominado a cena política local, com raras exceções, como foi o caso da eleição municipal de 1996, na qual, excepcionalmente, o candidato trabalhista saiu derrotado pela aliança PP/PMDB, que elegeu Ortiz Iboti Schröer prefeito municipal. A fragilidade e a desunião dos partidos mais à esquerda no espectro político-ideológico, bem como a predominância de um só partido na cena política, afetam negativamente a cultura política local. Além disso, vive-se, no município, uma carência de novas lideranças políticas, sociais e comunitárias e as que surgiram foram cooptadas por partidos tradicionais.

A cooptação das lideranças locais por partidos tradicionais enfraqueceu o movimento comunitário e de bairros. Afirma o sindicalista João Frantz:

Um exemplo: na década de $1960 / 70$ os vereadores e sindicalistas Valdenor Flores da Fonseca, João Filipin e Euclides Veriato da Cunha abandonaram "subitamente" as fileiras dos movimentos sociais ou comunitários para integrar forças políticas comandadas pela elite econômica de Ijuí na época. Mais casos podem ter ocorrido, enfraquecendo as entidades, associações de trabalhadores que haviam confiado nos seus representantes. A direita se deu conta das proporções ou rumos das organizações comunitárias e passou a agir/ou se impor (do seu jeito) ${ }^{11}$.

Por fim, para o professor Jaeme Callai, o período ditatorial também foi o responsável pela nulidade do surgimento de novas lideranças locais:

O período ditatorial anulou (cassou) lideranças populares; inibiu a ação ou o surgimento de outras; freou a participação popular autônoma. Diria que foi instituída a prática política do

\footnotetext{
${ }^{11}$ Entrevista concedida a Dejalma Cremonese, em Ijuí, 15 de outubro de 2005.
} 


\section{A SITUAÇÃO DAS AMÉRICAS: \\ DEMOCRACIA, CAPITAL SOCIAL E EMPODERAMENTO}

populismo (de direita) com a cooptação política de lideranças emergentes, e a manipulação popular ${ }^{12}$.

Avaliando-se a evolução do IDH (Índice de Desenvolvimento Humano) da Região Noroeste Colonial (RNC-RS), percebe-se que essa variável social apresentou, entre os anos de 1970 a 1990, um dos piores desempenhos, em comparação com outras regiões do Estado do Rio Grande do Sul. Segundo estudos de Oliveira (2001), a RNC-RS ocupou, em 1991, as antepenúltimas colocações nos indicadores de desenvolvimento humano e de incidência de pobreza, a penúltima colocação no índice de desigualdade de renda entre a população pobre e a quarta última posição no coeficiente de desigualdade de renda, devido aos seus componentes intra e intermunicipal. Além disso, a RNC-RS exibiu, no mesmo período, muitos municípios que se sobressaíram como os piores desempenhos no que se refere à incidência e ao grau de desigualdade de renda dos pobres. Dentre esses estavam Braga, Sede Nova, Redentora e Miraguaí. Conforme ainda o estudo de Oliveira (2001), nota-se que esses dois últimos municípios ocuparam as últimas e penúltimas colocações em relação aos indicadores de pobreza. Além da pobreza, os referidos municípios apresentam um dos piores resultados na desigualdade de renda entre suas populações ${ }^{13}$.

Segundo estudos de Stülp e Fochezatto (2004), praticamente $50 \%$ das regiões do Estado do Rio Grande do Sul estão em uma situação que pode ser

definida como círculo vicioso da pobreza: baixo PIB per capita, baixo crescimento econômico e redução da população. A RNC-RS faz parte desse grupo de regiões. Como demonstra o gráfico abaixo, o desempenho econômico da RNC/RS nos últimos 10 anos tem sido negativo: passou de 3,55\% na participação na economia do Estado para 2,63\%.

\footnotetext{
12 Entrevista concedida a Dejalma Cremonese, em Ijuí, 28 de outubro de 2005.

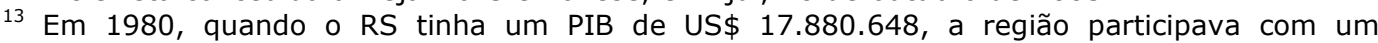
percentual de 3,3\%. Dessa data em diante, a participação percentual do PIB da região no PIB estadual declinou (salvo discreta evolução em 1992). Em 1994, quando o Estado estava com um PIB de US\$ 41.814.871, a região participava com 2,8\%. Isso mostra um relativo empobrecimento da região no período. Conferir os trabalhos de Oliveira (2001) e de Sperotto (2003).
} 
Gráfico 2 - A participação econômica da RNC no PIB do RS

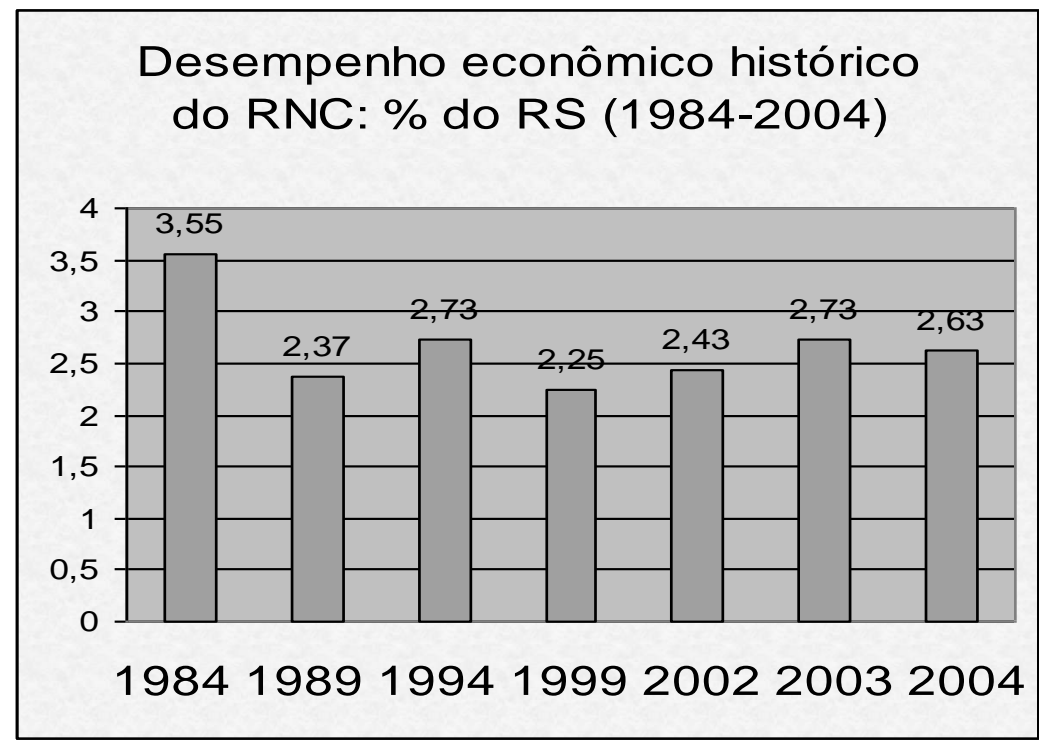

Fonte: Klering (2005).

Inserido na mesma realidade geográfica e econômica, o município de Ijuí, no mesmo período, não fugiu à regra. Segundo os dados do PNUD, o Índice de Desenvolvimento Humano (IDH) de Ijuí (nos setores de educação, de longevidade e geral municipal) pouco evoluiu durante os anos de 1970 a 1990, mas o IDH renda declinou dos anos 1980 a 1990. Os IDHs educação e de longevidade tiveram um baixo crescimento, mas linear na amostragem de 1970, 1980 e 1991, o que não aconteceu com o IDH renda e IDH geral municipal. Ambos tiveram um crescimento substancial entre as décadas de 1970 a 1980; no entanto, esse crescimento não se fez acompanhar entre os anos 1980 até 1991, inclusive houve uma retração no IDH renda, caindo de 0,951 em 1980 para 0,926 em 1991. O IDH municipal de 1980 a 1991 foi positivo, mas, abaixo da década anterior. Esses dados podem ser reflexos da crise em que entra o setor primário no início dos anos 1980, com o esgotamento da lavoura em grande escala (produção capitalista de monocultura de exportação) e o fim dos subsídios do governo, o que atingiu, além da agricultura, os setores a ela ligados, como a indústria de implementos agrícolas, comércio (lojas de insumos) e a própria Cotrijuí, que entrou em crise na mesma época. A nova metodologia do PNUD, a partir dos anos 1990 até 2000, demonstra outros números, mas se mantém a mesma tendência de baixo crescimento do IDH nos diferentes segmentos (conferir Gráficos 3 e 4). 


\section{A SITUAÇÃO DAS AMÉRICAS: \\ DEMOCRACIA, CAPITAL SOCIAL E EMPODERAMENTO}

Gráfico 3 - IDH de Ijuí (1970-1991)

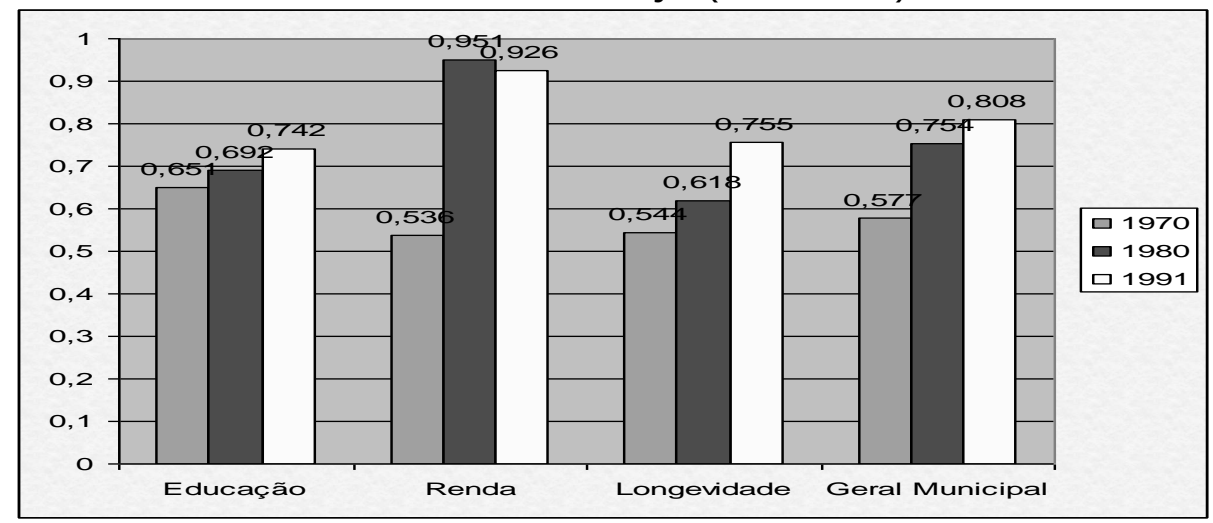

Fonte: PNUD/Atlas de Desenvolvimento Humano $(2006)^{14}$.

Gráfico 4 - Evolução do IDH de Ijuí (1991-2000)

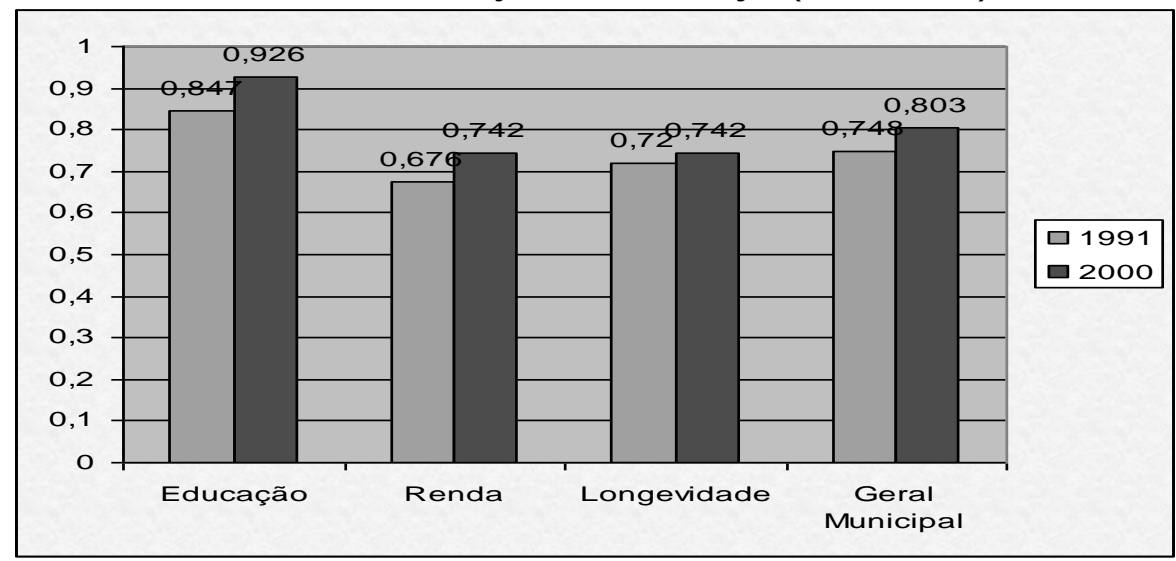

Fonte: PNUD/Atlas de Desenvolvimento Humano (2006).

Como demonstra o Gráfico 5, Ijuí tem declinado na evolução do PIB em relação aos demais municípios do Rio Grande do Sul nos últimos quinze anos, passando da $22^{a}$ colocação para a $27^{a}$ em 2004, apresentando uma melhor colocação no ano de 2009 , quando alcança a $24^{a}$ colocação.

${ }^{14} \mathrm{O}$ Gráfico 3 se refere à metodologia anterior e o Gráfico 4 à metodologia atual. Segundo o PNUD, existem diferenças metodológicas entre os dois lançamentos. No cálculo de IDH-E (educação), na metodologia anterior, era composto pela taxa de alfabetização e pela média de anos de estudo. No novo Atlas, a média de anos de estudo foi substituída pela taxa bruta de frequência à escola nos três níveis de ensino, tornando mais semelhante ao IDH internacional. Já o IDH-R (renda): a fórmula de cálculo mudou. Antes, ela apresentava um forte redutor apenas para rendas que ultrapassavam ao valor médio mundial. No novo Atlas, seguindo a mudança realizada no IDH internacional em 1999, a fórmula de redução é mais suave e aplicada em todos os valores, a partir de uma função logarítmica. E, por último, no IDH-L (longevidade) o indicador de esperança de vida ao nascer foi recalculado para todos os municípios brasileiros, porque foi implementada uma atualização nos cálculos de sobrevivência-padrão (PNUD, 2006). 
Gráfico 5 - Colocação do PIB de Ijuí em relação aos demais municípios do RS Ordem Crescente.

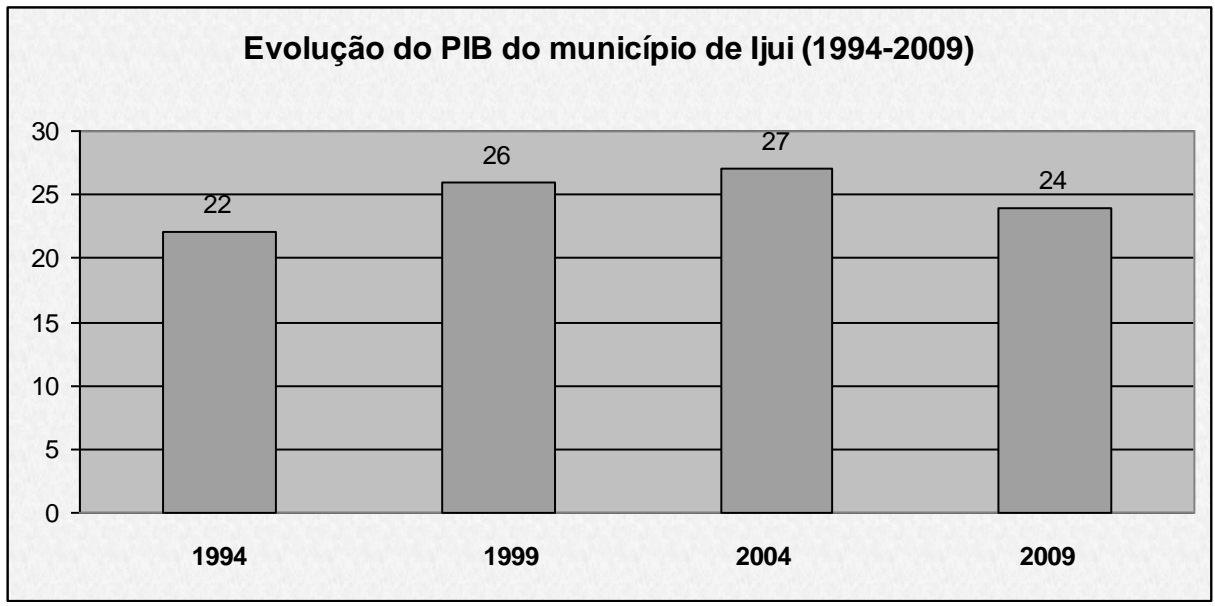

Fonte: $\mathrm{FEE}^{15}$.

Por fim, esta seção procurou responder à problemática central do estudo, que foi tratar das variáveis que mais influenciaram para o declínio dos níveis de participação político-social (capital social) em Ijuí nos últimos tempos.

Acredita-se que as hipóteses foram, igualmente, comprovadas. Comprovou-se que a incidência de práticas cada vez menos recorrentes de ações cooperativas, associativistas, participativas e comunitárias acabaram causando variações negativas nos níveis de capital social de Ijuí. Também se comprovou que a redução de práticas participativas, de confiança, causou maior fragmentação social, insegurança, clientelismo político e declínio do IDH. Da mesma forma, percebeu-se que a redução da participação cívica e do capital social de uma cidade ou região pode inibir o crescimento econômico e o desenvolvimento social, bem como pode aumentar a fragmentação social, reduzir o desempenho político e a estabilidade democrática de um país.

\section{Considerações finais}

O objetivo central da investigação aqui empreendida foi analisar os níveis de participação político-social em âmbito local, ao tratar, especificamente, do município de Ijuí - Noroeste do Estado do Rio Grande do Sul. A partir da interpretação da investigação empírica da variação dos níveis de capital social dos cidadãos ijuienses, o estudo apontou as prováveis razões para a variação negativa do capital social no município.

${ }^{15}$ Disponível em: <http://www.fee.tche.br/sitefee/pt/content/resumo/pg_municipios_detalhe.ph p?municipio=Iju\%ED>. Acesso em: 03 mar. 2012. 


\section{A SITUAÇÃO DAS AMÉRICAS: \\ DEMOCRACIA, CAPITAL SOCIAL E EMPODERAMENTO}

A comprovação desses resultados foi possível a partir de pesquisas junto aos dados eleitorais do TRE, dados econômicos (IDH e PIB/per capita) do IBGE e da FEE, dados comparativos entre os surveys de 1968 e 2005, além de depoimentos de lideranças políticas, educacionais e comunitárias.

Inicialmente discorreu-se sobre a análise conceitual do capital social e da participação. Em um segundo momento, de caráter mais analítico, procurou-se evidenciar a variação negativa do capital social em Ijuí. Depoimentos de lideranças políticas locais confirmam o declínio da sociabilidade da comunidade ijuiense. Impera o familismo amoral de Banfield, em que se procura maximizar a vantagem material e imediata da família nuclear e supor que todos os outros agirão da mesma forma. Ou seja, entre os três tipos de capital social desenvolvidos no trabalho (bonding, bridging e linking), a sociedade ijuiense pode ser considerada do tipo bonding (relações para dentro - laços fortes), onde práticas de solidariedade se dão apenas entre pessoas dos mesmos laços étnicos, ou grupos familiares fechados. Além do mais, a sociedade ijuiense apresenta altos índices de insegurança, insatisfação e frustração: $50 \%$ da população sente-se insegura ao andar nas ruas e $73 \%$ avalia o serviço da segurança pública como "ruim" ou "péssima". O êxodo rural crescente das últimas décadas (migrantes provenientes da própria região) aprofundou os problemas da cidade, tais como violência, desemprego, ausência de saneamento básico e déficit imobiliário, que são os problemas mais evidentes de Ijuí. Por outro lado, convém referir que Ijuí tem perdido boa parte de seu capital humano qualificado, que busca em outras regiões as oportunidades de trabalho que o município não lhes tem dado.

No que se refere às manifestações da política convencional, nota-se que a participação em reuniões partidárias reduziu, bem como em partidos políticos e em comícios. Da mesma forma, a participação dos eleitores tem diminuído nas últimas eleições municipais, ficando em torno de $86 \%$. O interesse por assuntos políticos tem decrescido, igualmente. Os velhos vícios da cultura política tradicional encontram espaço também em nível local, pois ainda impera o clientelismo, o patrimonialismo e o personalismo. Há pouca alternância no poder local, havendo predominância das mesmas famílias no poder há décadas. Há forte desconfiança interpessoal e nas instituições políticas, além de o PIB e de o IDH do município estarem estagnados.

Durante os anos 1950 e 1960, a população do município produziu uma notável reação à crise dos modelos social e econômico enfrentados pelos colonos diante da modernização da agricultura, que consistiu na criação de espaços sociais de debate, de educação e de realização institucional. Esses espaços, convertidos em instituições, foram de tal forma originais, que acabaram marcando a identidade do município e da região: a FAFI/Fidene/Unijuí, o Movimento Comunitário de Base (MCB) e a Cotrijuí, entre outros, foram exemplos bem-sucedidos de capital social na época. Mesmo assim, no entanto, já no final da década de 1970, Ijuí empobrecera politicamente, a participação comunitária declinara, as lideranças locais foram cooptadas pelas forças políticas conservadoras e seguiu empobrecendo-se 


\section{A SITUAÇÃO DAS AMÉRICAS: DEMOCRACIA, CAPITAL SOCIAL E EMPODERAMENTO}

com a perda do protagonismo das demais instituições. Politicamente, os sucessivos governos de um único partido (Arena e, posteriormente, o PDT), cada vez mais paternalistas, personalistas e populistas, foram incapazes de organizar as oportunidades de desenvolvimento e fecharam o quadro da pobreza política.

Enfim, acredita-se que a hipótese central deste estudo foi confirmada, na medida em que evidenciou práticas cada vez menos recorrentes de ações cooperativas, associativistas, participativas e comunitárias nas últimas três décadas, ocasionando uma variação negativa do capital social de Ijuí. Houve um declínio de manifestações cívicas com a diminuição da participação política convencional (reuniões partidárias, partidos políticos, comícios, eleições); altos índices de desconfiança (interpessoal, instituições políticas e insegurança); redução do associativismo e cooperação (individualismo, familismo amoral, baixa participação comunitária), além da estagnação econômica e da qualidade de vida (segundo números referentes ao PIB e ao IDH municipal) - são algumas manifestações do impacto negativo do capital social de Ijuí que este artigo procurou evidenciar no decorrer de suas páginas.

Dejalma Cremonese é Doutor em Ciência Política pela UFRGS e professor do Departamento de Ciências Sociais da UFSM.

E-mail:dcremoisp@yahoo.com.br

\section{Referências}

ALLEBRANDT, Sérgio Luís. A participação da sociedade na gestão pública local e na produção das políticas: a atuação dos conselhos municipais de Ijuí - RS, de 1989 a 2000. Ijuí: Ed. Unijuí, 2002. (Série Dissertações de Mestrado, 32).

ALVES, Douglas Santos; VISCARRA, Simone. Capital social, satisfação e as diferentes formas de participação política. Revista Debates, Porto Alegre, v. 1, n. 1, (número extraordinário), p. 1-24, 2005.

AVELAR, Lúcia; CINTRA, Antônio Octávio (Orgs.). Sistema político brasileiro: uma introdução. São Paulo: Unesp, 2004.

BANFIELD, Edward C. The moral basis of a blackward society. New York: Free Press, 1958.

BAQUERO, Marcello. A vulnerabilidade dos partidos políticos e a crise da democracia na América Latina. Porto Alegre: Universitária/UFRGS, 2000.

(Org.). Reinventando a sociedade na América Latina: cultura política, gênero, exclusão e capital social. Porto Alegre: UFRGS, 2001. 


\section{A SITUAÇÃO DAS AMÉRICAS: \\ DEMOCRACIA, CAPITAL SOCIAL E EMPODERAMENTO}

(Org.). Cultura política, democracia e capital social. Revista de Sociologia e Política, Curitiba, n. 21, nov. 2003.

. Um modelo integrado de democracia social na América Latina. Revista Debates, Porto Alegre, v. 1, n. 1, (número extraordinário), p. 5-55, 2005.

BORBA, Julian. Comportamento político e capital social na América do Sul. Revista Debates, Porto Alegre, v. 1, n. 1, (número extraordinário), p. 55-68, 2005.

COLEMAN, James S. The social capital in the creation of human capital. American Journal of Sociology, Chicago, v. 94, Supplement, p. 95-120, jun. 1988.

FUKUYAMA, Francis. Capital social. In: HARISSON, Lawrence E.; HUNTINGTON, Samuel P. (Orgs.). A cultura importa: os valores que definem o progresso humano. Rio de Janeiro: Record, 2002. p. 155-172.

HANIFAN, Lyda. The rural school community center. Annals of the American Academy of Political and Social Science, Philadelphia, v. 67, n. 1, p. 130-138, sep. 1916.

HIGGINS, Silvio Salej. Fundamentos teóricos do capital social. Chapecó: Argos, 2005.

IBGE. Instituto Brasileiro de Geografia e Estatística. Cidades. 2010. Disponível em: <http://www.ibge.gov.br/>. Acesso em: 14 jun. 2005.

JACOBS, Jane. The death and life of great American cities. New York: Random House, 1961.

KLERING, Luis Roque. Evolução do IDH dos municípios do RS. 2005. Disponível em: <www.terragaucha.com.br>. Acesso em: 14 abr. 2006.

MINISTÉRIO DA JUSTIÇA - Secretaria Nacional de Segurança Pública. Custos sociais e econômicos da criminalidade no Brasil. 2003. Disponível em: <http://www.unodc.org/pdf/brazil/pp_6_custos_sociais_pt.pps>. Acesso em: 30 abr. 2006.

NORRIS, Pipa. Democratic Phoenix: reinventing political activism. Cambridge: Cambridge University Press, 2002. Disponível em: <http://astro.temple.edu/ rkolodny/documents/Review\%20of\%20Norris\%20 Democratic\%20Phoenix.pdf>. Acesso em: 14 abr. 2012. 
OLIVEIRA, Júlio César. Desenvolvimento humano, desigualdade de renda e pobreza nos conselhos regionais de desenvolvimento e municípios do RS entre 1970 e 1991. 2001. 275 f. Tese (Doutorado em Economia) - Programa de Pós-Graduação em Economia, UFRGS, Porto Alegre, 2001.

OUTHWAITE, Willian; BOTTOMORE, Tom. Participação. In: (Eds.). Dicionário do pensamento social do século XX. Rio de Janeiro: Zahar, 1996. p. 558-559.

PNUD. Programa das Nações Unidas para o Desenvolvimento. Índice de desenvolvimento humano - municipal. 1991 e 2000. Disponível em: <http://www.pnud.org.br/home/>. Acesso em: 14 abr. 2006.

- Atlas de Desenvolvimento Humano 2006. Disponível em: <www.pnud.org.br>. Acesso em: 13 mai. 2006.

PUTNAM, Robert. Comunidade e democracia: a experiência da Itália Moderna. Rio de Janeiro: FGV, 2002.

SPEROTTO, Leandro Tiago. O desenvolvimento econômico da região Noroeste do Rio Grande do Sul, 1900-2000. 2003. 205 f. Dissertação (Mestrado em Economia), Programa de Pós-Graduação em Economia, PUCRS, Porto Alegre, 2003.

STÜLP, Valter J.; FOCHEZATTO, Adelar. A evolução das disparidades regionais no Rio Grande do Sul: uma aplicação de matrizes de Markov. Revista Nova Economia, Belo Horizonte, v. 14, n. 1, p. 39-66, jan.-abr. 2004.

TOCQUEVILLE, Alexis de. A democracia na América. 3. ed. Belo Horizonte: Itatiaia, 1969.

TRINDADE, Hélgio Henrique Casses. Ijuí 1968: comparação de dados. Pesquisas eleitorais no Rio Grande do Sul. Porto Alegre: Núcleo de Pesquisa e Documentação da Política Rio-grandense, 1968. [Apostila].

VALDIVIESO, Patrício. Capital social e desenvolvimento democrático: Porto Alegre (Brasil) e Santiago do Chile. Revista Brasileira de Ciências Sociais, São Paulo, v. 24, n. 69, p. 93-114, fev. 2009. Disponível em: <http://www.scielo.br/scielo.php?pid=S0102-69092009000100007\&script= sci_arttext\#back6>. Acesso em: 12 abr. 2012.

Texto recebido em 24/02/2012. Aprovado em 11/04/2012. 